\title{
Transverse Comparisons Between Ultrasound and Radionuclide Parameters in Children with Pelvi-Ureteric Junction Obstruction
}

\author{
Samer Malak Botros, Ali Hagag Ali, Norhan Osama shawky \\ Radiology Department -Faculty of Medicine- Ain Shams University \\ Corresponding author: Norhan Osama shawky, Email: norhanmedecine@gmail.com
}

\begin{abstract}
Pelvi-ureteric junction (PUJ) obstruction is one of the causes of an obstructive uropathy which may be congenital or acquired. Ureteropelvic junction (UPJ) obstruction is a blockage at the point where ureters attaches to the bladder. This blocks the flow of urine out of the kidney, Urine can build up and damage the kidney, so radiologic imaging is crucial in diagnosing UPJ obstruction. It seemed therefore interesting to determine if some US parameters could predict the radionuclide parameters and which ultrasound parameter most influencing the kidney function. The initial step was to grade the severity of hydronephrosis, calyceal dilatation and cortical thinning, although it was easy for us to classify the importance of hydronephrosis in three groups according to anteroposterior diameter (APD). AP diameter of renal pelvis and differential renal function were the most effective parameters for surgical decision. These parameters can be used for appropriate management of antenatal hydronephrosis.
\end{abstract}

Key words: UPJ: Uereteropelvic junction, US: Ultrasonography, APD: anteroposterior diameter

\section{INTRODUCTION}

Pelvi-ureteric junction (PUJ) obstruction/ stenosis is one of the causes of an obstructive uropathy which may be congenital or acquired with a congenital PUJ obstruction being one of the commonest causes of antenatal hydronephrosis ${ }^{(1)}$.

Several methods are used in diagnosing upper urinary tract obstruction as: ultrasonography, intravenous pyelogram, un-enhanced CT,diuretic renography, magnetic resonance urography and antegrade or retrograde pyelography ${ }^{(2)}$.

It may present in both paediatric and adult populations although they tend to have differing aetiology. The estimated incidence in paediatric populations is $\sim 1$ per 1000-2000 new-borns ${ }^{(1)}$.

PUJ obstruction is most commonly unilateral but is reported to be bilateral in $\sim 30 \%$ (range 10-49\%) of cases ${ }^{(3)}$.

Radiologic imaging is crucial in diagnosing UPJ obstruction. The diagnosis of UPJ obstruction signifies functionally impaired transport of urine from the renal pelvis into the ureter. Because the increased renal pelvic pressure from obstruction may lead to progressive renal injury and embarrassment, correct diagnosis is clinically important ${ }^{(3)}$.

Current radiologic standards define hydronephrotic kidneys as those with an anteroposterior (AP) diameter at the renal pelvis of greater than $4 \mathrm{~mm}$ at a gestational age of less than 33 weeks and an AP diameter of greater than $7 \mathrm{~mm}$ at a gestational age of 33 weeks or older. An abnormal initial ultrasonogram should be followed up with another ultrasonogram after 4 weeks in severe cases or after 33-34 weeks in mild to moderate cases $^{(4)}$.
Not uncommonly, asymptomatic UPJ obstruction is discovered in older children or adults when radiologic studies, such as ultrasonography, intravenous pyelography (IVP), computed tomography (CT) scanning, or magnetic resonance imaging (MRI), are performed for other reasons. The use of intravenous contrast material with nephrogenic and delayed excretion phases during CT scanning may provide qualitative information regarding obstruction, but in general, CT should be avoided because of the inherent high radiation dose. When hydronephrosis is seen when UPJ obstruction is suspected, diuretic renography is more accurate than $\mathrm{CT}^{(4)}$.

Intravenous pyelography (IVP) has historically been the primary study used to diagnose UPJ obstruction in adults, because it also provides anatomic and functional information. However, ultrasonography is preferred as the initial study in children because of its nonionizing and non-invasive nature ${ }^{(5)}$.

CT may depict ureteropelvic junction (UPJ) obstruction when it is used as a primary study for evaluating common presenting symptoms. In older children, the modality is useful for assessing causes of acquired UPJ and ureteral obstruction (e.g., stones, tumors, retroperitoneal processes). Often, hydronephrosis is found incidentally on CT scans, and further studies are needed to distinguish UPJ obstruction from nonobstructive hydronephrosis ${ }^{(\boldsymbol{(})}$.

Cortical thinning in a hydronephrotic kidney may be seen on $\mathrm{CT}$ scans and may be predictive of ipsilateral renal function. The use of intravenous contrast material with nephrogenic and delayed excretory-phase images also may be helpful in determining whether renal function and excretion are impaired ${ }^{(6)}$. 


\section{AIM OF THE WORK}

The aim of the study is to correlate between ultrasound parameters and dynamic scintigraphic parameters in children with pelviureteric junction obstruction (PUJO), the importance of each factor, and which of the ultrasound parameters most reflecting the renal function which is determined by the level of differential renal function (DRF) and the quality of renal drainage after a furosemide challenge, and if we can predict, on the basis of ultrasound parameters, the patient in whom radionuclide renography can be avoided. Also the role of both ultrasound and radionuclide parameters in deciding on surgery.

\section{PATIENTS AND METHODS}

Type of Study: Cross sectional study, we retrospectively analyzed the medical charts of 20 consecutive children with presumed unilateral PUJO. The diagnosis of pelviureteric junction stenosis was based on a complete imaging and radionuclide work-up (US and renography). The study was approved by the Ethics Board of Ain Shams University.

Study Setting: All US examinations and all renogram studies at the radiology Department of Ain Shams University hospitals.

Study Period: 6 months for data collection.

Study Population: Inclusion Criteria: Suspected children (boys or girls, both are included) who are presented with urinary tract infection (UTI), prenatal hydronephrosis, abdominal/flank pain, abdominal mass and hematuria.

Exclusion Criteria: Children with bilateral PUJO or with hydroureter. Any abnormality of the contralateral kidney (vesicoureteral reflux, duplex kidney, renal agenesis). All children with an anteroposterior renal pelvic diameter (APD) less than $15 \mathrm{~mm}$ were also excluded.

Sampling Method: convenience sample.

Sample Size: 20 children (boys and girls).

Ethical Considerations: The whole procedures are explained in details to the parents and the children (if old enough) and the parents/child receive detailed written information which explains the entire procedure and any possible risks that may happen, this is called the informed consent. The Informed consent is signed by the legal guardian(s) of the child.
Study Tools: Serum creatinine level. Ultrasound machine with suitable probe. Radioisotope unit with radionuclide substance. Medications that is used as: furosemide.

Radiopharmaceutical: ${ }^{99 \mathrm{~m}} \mathrm{Tc}$-diethylene triamine pentaacetic acid (99mTcDTPA) is a glomerular agent. The biologic half-life is less than $2.5 \mathrm{~h}$, and $95 \%$ of the administered dose is cleared by $24 \mathrm{~h}$. The recommended administered dose is 3.7 MBq (100 mCi) per kilogram of body weight (minimum, $37 \mathrm{MBq}$ ).

Procedure: It includes the following steps: 1 . Collimator: LEAP parallel hole, placed below the child. 2 . Field of view: from xiphisternum to the symphysis pubis. 3. The study is a dynamic renal scan with the child in supine position and with child's back to the camera. Serial images (64 64 or $128 \bullet 128$ matrix) are acquired: First 3060 seconds (frame $/ 0.5 \mathrm{sec}$ ) to detect renal perfusion. First 2-3 minutes (frame / $0.5 \mathrm{sec}$ ) to measure GFR. Next 20-30 minutes (frame/min), and delayed films after 2 hours for detection of whole collecting system. 4. Plotting of time activity curve and renogram is done. 5 . Time activity curve: it is plotted using initial fast frame sequences (Plot activities within the aorta and both kidneys against time).It is used to estimate the renal blood flow (RBF) from the aorta. 6.Renogram: It estimates the kinetics of the tracer within the renal parenchyma in relation to time. Renogram shows: A.Initial vascular phase (I): rapid increase of activity due to renal perfusion (tracer reach the kidney with blood). B.Uptake phase (II): further increase in the tracer activity due to tracer uptake by glomeruli (renal parenchyma) with minimal washout. C. Declining phase (III): decrease the activity due to tracer washout from kidneys due to excretion with urine. 7. IV lasix (The dose equals 1.0 $\mathrm{mg} / \mathrm{kg}$, with a usual maximum dose of $40 \mathrm{mg}$ ) is given after 10-15 minutes from injection to differentiate between physiological stasis and obstruction. 8. Differential renal function (DRF) was calculated using the integral method (number of counts in each kidney during the same time interval of $1-2 \mathrm{~min}$ ) after background correction using a one-pixel perirenal area.

Statistical Package: The software used was SPSS.

Statistical Analysis: Appropriate descriptive and inferential statistical tests will be used.

Recorded data were analyzed using the statistical package for social sciences, version 20.0 (SPSS Inc., Chicago, Illinois, USA). Quantitative data were expressed as mean \pm standard deviation (SD). Qualitative data were expressed as frequency and percentage. 
The following tests were done: Chi-square (X2) test of significance was used in order to compare proportions between two qualitative parameters. Fisher's exact test: was used to examine the relationship between two qualitative variables when the expected count is less than 5 in more than $20 \%$ of cells Pearson's correlation coefficient (r) test was used for correlating data. The confidence interval was set to $95 \%$ and the margin of error accepted was set to 5\%. So, the p-value was considered significant as the following: Probability (P-value): $\mathrm{P}$-value $\leq 0.05$ was considered significant. Pvalue $\leq 0.001$ was considered as highly significant. Pvalue $>0.05$ was considered insignificant.

\section{RESULTS}

We selected for all comparisons the first available renogram (generally between 2 and 12 months) and the US examination performed at the same time.

Table (1): Summary of correlation between ultrasound and radionucleotide parameters in diseased group.

\begin{tabular}{|l|c|c|c|c|}
\hline \multicolumn{1}{|c|}{ Us/Isotope } & DFR & TTP & T1/2 & $\begin{array}{c}\text { Quality of renal } \\
\text { drainage }\end{array}$ \\
\hline APD & SN & SP & SP & SN \\
\hline PT & SP & NR & NR & NR \\
\hline CD & SN & SN & NR & NR \\
\hline
\end{tabular}

SN: Significant Negative, SP: Significant Positive, NR: No correlation

Table (2): Isotope parameters distribution of the study group.

\begin{tabular}{|l|c|}
\hline \multicolumn{1}{|c|}{ Isotope parameters } & Range (Mean+SD \\
\hline$D R F \% R K$ & $15.3-78(49.85 \pm 18.45)$ \\
\hline$D R F \% L K$ & $22-84.6(50.21 \pm 18.51)$ \\
\hline$T T P(\min ) R K$ & $0.6-19.5(7.98 \pm 6.58)$ \\
\hline$T T P(\min ) L K$ & $0.8-20.5(6.50 \pm 4.95)$ \\
\hline$T 1 / 2(\min ) R K$ & $1.44-25(9.87 \pm 6.11)$ \\
\hline$T 1 / 2($ min $) L K$ & $0-22(7.15 \pm 6.11)$ \\
\hline Quality of renal drainage & Frequency $(\%)$ \\
\hline Poor & $13(65 \%)$ \\
\hline Good & $7(35 \%)$ \\
\hline
\end{tabular}

This table shows that the mean of DRF\% RK 49.85 \pm 18.45 DRF\% LK 50.21 \pm 18.51 , TTP (min) RK 7.98 \pm 6.58 , TTP (min) LK 6.50 \pm 4.95 , T

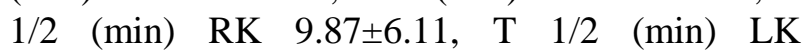
$7.15 \pm 6.11$, Quality of renal drainage is Poor 13 $(65 \%)$ and Good in 7 (35\%) of isotope parameters.

Table (3): Ultrasound parameters distribution of the study group.

\begin{tabular}{|l|l|}
\hline Ultrasound parameters & Range (Mean+SD \\
\hline$A P D(\mathrm{~mm}) R K$ & $0-60(21.55 \pm 19.30)$ \\
\hline$A P D(\mathrm{~mm}) L K$ & $0-60(13.50 \pm 20.91)$ \\
\hline$C D($ calyceal dilatation $)(\mathrm{mm}) R K$ & $0-15(4.86 \pm 4.52)$ \\
\hline$C D($ mm $)$ LK & $0-11(3.60 \pm 4.60)$ \\
\hline$P T($ parenchymal thickness $)(\mathrm{mm}) R K$ & $2-20(8.21 \pm 3.96)$ \\
\hline$P T(\mathrm{~mm}) L K$ & $2-20(9.72 \pm 5.36)$ \\
\hline
\end{tabular}

This table shows that the mean of APD (mm) RK 21.55 \pm 19.30, APD (mm) LK 13.50 $\pm 20.91, \mathrm{CD}(\mathrm{mm}) \mathrm{RK} 4.86 \pm 4.52, \mathrm{CD}(\mathrm{mm})$

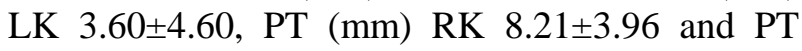
(mm) LK 9.72 \pm 5.36 of ultrasound parameters.

Table (4): Isotope and ultrasound parameters distribution of the study group,

\begin{tabular}{|c|c|}
\hline The affected side & Range (Mean+SD \\
\hline \multicolumn{2}{|c|}{ Isotope parameters of the affected kidney } \\
\hline DRF\% & $15.3-66.6(37.25 \pm 13.02)$ \\
\hline TTP (min) & $0.8-19.5(8.78 \pm 6.26)$ \\
\hline $\mathrm{T} 1 / 2(\min )$ & $1.44-25(11.34 \pm 7.19)$ \\
\hline Quality of renal drainage & Frequency $(\%)$ \\
\hline Poor & $13(65 \%)$ \\
\hline Good & $7(35 \%)$ \\
\hline \multicolumn{2}{|c|}{ Ultrasound parameters of the affected kidney } \\
\hline APD $(\mathrm{mm})$ & $18-60(35.05 \pm 14.05)$ \\
\hline $\mathrm{CD}(\mathrm{mm})$ & $2-15(7.91 \pm 2.82)$ \\
\hline PT (mm) & $2-20(6.83 \pm 4.38)$ \\
\hline
\end{tabular}

This table shows the scintigraphic and sonographic parameters of the affected kidney in the study population with the mean of DRF\% $37.25 \pm 13.02$, TTP $(\mathrm{min}) 8.78 \pm 6.26$ and T $1 / 2(\mathrm{~min})$ $11.34 \pm 7.19$ of Isotope parameters, also mean of APD (mm) 35.05 $\pm 14.05, \mathrm{CD}(\mathrm{mm}) 7.91 \pm 2.82$ and PT $(\mathrm{mm}) 6.83 \pm 4.38$ of Ultrasound parameters.

Table (5): Normal and abnormal isotope and ultrasound parameters distribution of the study group.

\begin{tabular}{|l|c|}
\hline The affected side & Frequency $(\%)$ \\
\hline Isotope parameters & \\
\hline DRF\% & \\
Normal $\geq 45$ & $4(20.0 \%)$ \\
Abnormal $<45$ & $16(80.0 \%)$ \\
\hline TTP $(\mathbf{m i n})$ & $7(35.0 \%)$ \\
Normal $\leq 6$ & $13(65.0 \%)$ \\
Abnormal $>6$ & \\
\hline T 1/2 $($ min) & $8(40.0 \%)$ \\
Normal $<10$ & $12(60.0 \%)$ \\
Abnormal $\geq 10$ or 0 & \\
\hline Quality of renal drainage & $7(35.0 \%)$ \\
Good & $13(65.0 \%)$ \\
\hline Poor & \\
\hline Ultrasound parameters & \\
\hline APD $(\mathbf{m m})$ & $1(5.0 \%)$ \\
$15-19$ & $7(35.0 \%)$ \\
$20-29$ & $12(60.0 \%)$ \\
\hline 30 & \\
\hline CD $(\mathbf{m m})$ & $4(20.0 \%)$ \\
$0-5$ & $14(70.0 \%)$ \\
$6-10$ & $2(10.0 \%)$ \\
\hline$>10$ & \\
\hline PT $(\mathbf{m m})$ & $12(60.0 \%)$ \\
Normal $\geq 6$ & $8(40.0 \%)$ \\
Abnormal $<6$ & \\
\hline
\end{tabular}

This table shows that the DRF\% The normal $\geq 45\{4\}(20.0 \%)$, and the abnormal $<45$ $\{16\}(80.0 \%)$, TTP (min) the normal $\leq 6$ $\{7\}(35.0 \%)$, and the abnormal $>6\{13\}(65.0 \%)$, $\mathbf{T}$ $\mathbf{1} / \mathbf{2}$ (min) the normal $<10\{8\}(40.0 \%)$, and the 
abnormal $\geq 10$ or $0\{12\}(60.0 \%)$ and the Quality of renal drainage; Good $7(35.0 \%)$ and Poor 13 $(65.0 \%)$ of Isotope parameters.

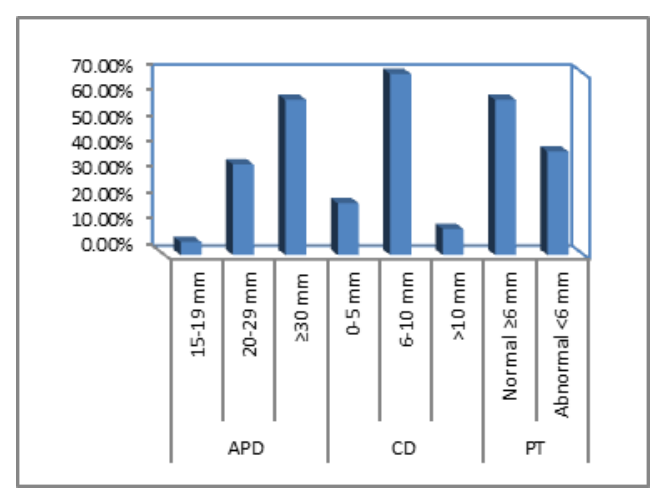

Fig.(1): Ultrasound parameters distribution of the diseased side in the study group.

Table (6): Correlation between DRF\% and ultrasound parameters in the affected side in the study group.

\begin{tabular}{|c|c|c|c|c|c|c|}
\hline \multirow{3}{*}{$\begin{array}{l}\text { Ultrasound } \\
\text { parameters }\end{array}$} & \multicolumn{4}{|c|}{ DRF\% } & \multirow{2}{*}{\multicolumn{2}{|c|}{ Chi-square test }} \\
\hline & \multicolumn{2}{|c|}{$\begin{array}{c}\text { Normal } \geq 45 \\
(N=4)\end{array}$} & \multicolumn{2}{|c|}{$\begin{array}{c}\text { Abnormal }<45 \\
(N=16)\end{array}$} & & \\
\hline & No. & $\%$ & No. & $\%$ & $\mathrm{x}^{2}$ & p-value \\
\hline \multicolumn{7}{|l|}{ APD (mm) } \\
\hline $15-19(\mathrm{~N}=1)$ & 1 & $100.0 \%$ & 0 & $0.0 \%$ & \multirow{3}{*}{9.286} & \multirow{3}{*}{$0.010^{*}$} \\
\hline $20-29(\mathrm{~N}=7)$ & 3 & $42.9 \%$ & 4 & $57.1 \%$ & & \\
\hline$\geq 30(\mathrm{~N}=12)$ & 0 & $0.0 \%$ & 12 & $100.0 \%$ & & \\
\hline \multicolumn{7}{|l|}{ CD (mm) } \\
\hline $0-5(\mathrm{~N}=4)$ & 2 & $50.0 \%$ & 2 & $50.0 \%$ & \multirow{3}{*}{7.036} & \multirow{3}{*}{$0.022^{*}$} \\
\hline 6-10 (N=14) & 2 & $14.3 \%$ & 12 & $85.7 \%$ & & \\
\hline$>10(\mathrm{~N}=2)$ & 0 & $0.0 \%$ & 2 & $100.0 \%$ & & \\
\hline \multicolumn{7}{|l|}{ PT (mm) } \\
\hline $\begin{array}{l}\text { Normal } \geq 6 \\
(\mathrm{~N}=12)\end{array}$ & 4 & $33.3 \%$ & 8 & $66.7 \%$ & \multirow{2}{*}{5.333} & \multirow{2}{*}{$0.048^{*}$} \\
\hline $\begin{array}{l}\text { Abnormal <6 } \\
(\mathrm{N}=8)\end{array}$ & 0 & $0.0 \%$ & 8 & $100.0 \%$ & & \\
\hline $\begin{array}{l}15-19 \text { vs. } 20-29 \mathrm{AP} \\
15-19 \text { vs. } \geq 30 \mathrm{APD} \\
20-29 \text { vs. } \geq 30 \mathrm{APD}\end{array}$ & $\begin{array}{l}\mathrm{p}=0 \\
=<0 . \\
=0.0\end{array}$ & $* *$ & & $\begin{array}{l}\text { s. } 6-10 \mathrm{C} \\
\text { s. }>10 \mathrm{C} \\
\text { vs. }>10\end{array}$ & $\begin{array}{l}=0.03 \\
=0.759 \\
p=0.02\end{array}$ & \\
\hline
\end{tabular}

This table shows statistically significant negative correlation between DRF\% and APD, CD and PT, this correlation is being more evident between DRF\% and APD.

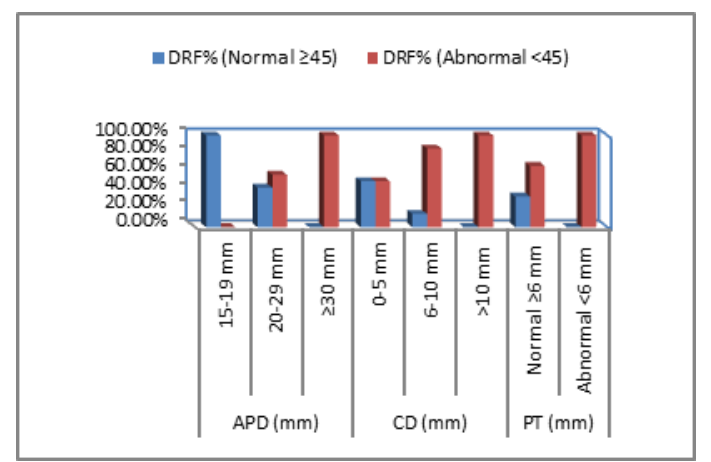

Fig. (2): Bar chart correlation between DRF\% and ultrasound parameters in the study group.
Table (7): Correlation between TTP and ultrasound parameters of the affected side in the study group.

\begin{tabular}{|c|c|c|c|c|c|c|}
\hline \multirow{3}{*}{$\begin{array}{l}\text { Ultrasound } \\
\text { parameters }\end{array}$} & \multicolumn{4}{|c|}{ TTP (min) } & \multirow{2}{*}{\multicolumn{2}{|c|}{ Chi-square test }} \\
\hline & \multicolumn{2}{|c|}{ Normal $(\mathrm{N}=7)$} & \multicolumn{2}{|c|}{ Abnormal (N=13) } & & \\
\hline & No. & $\%$ & No. & $\%$ & $x^{2}$ & p-value \\
\hline \multicolumn{7}{|l|}{ APD (mm) } \\
\hline $15-19(\mathrm{~N}=1)$ & 1 & $100.0 \%$ & 0 & $0.0 \%$ & \multirow{3}{*}{5.999} & \multirow{3}{*}{$0.037 *$} \\
\hline $20-29(\mathrm{~N}=7)$ & 2 & $28.6 \%$ & 5 & $71.4 \%$ & & \\
\hline$\geq 30(\mathrm{~N}=12)$ & 4 & $33.3 \%$ & 8 & $66.7 \%$ & & \\
\hline \multicolumn{7}{|l|}{$\mathrm{CD}(\mathrm{mm})$} \\
\hline $0-5(\mathrm{~N}=4)$ & 2 & $50.0 \%$ & 2 & $50.0 \%$ & \multirow{3}{*}{4.476} & \multirow{3}{*}{$0.048 *$} \\
\hline $6-10(\mathrm{~N}=14)$ & 5 & $35.7 \%$ & 9 & $64.3 \%$ & & \\
\hline$>10(\mathrm{~N}=2)$ & 0 & $0.0 \%$ & 2 & $100.0 \%$ & & \\
\hline \multicolumn{7}{|l|}{ PT (mm) } \\
\hline $\begin{array}{l}\text { Normal } \geq 6 \\
(\mathrm{~N}=12)\end{array}$ & 3 & $25.0 \%$ & 9 & $75.0 \%$ & \multirow{2}{*}{1.319} & \multirow{2}{*}{0.251} \\
\hline $\begin{array}{l}\text { Abnormal <6 } \\
(\mathrm{N}=8)\end{array}$ & 4 & $50.0 \%$ & 4 & $50.0 \%$ & & \\
\hline $15-19$ vs. $20-29$ & & 785 & & $6-10 \mathrm{C}$ & $=0.94$ & \\
\hline $\begin{array}{l}15-19 \text { vs. } \geq 30 \mathrm{~A} \\
20-29 \text { vs }>30 \mathrm{~A}\end{array}$ & $\begin{array}{l}p=c \\
p=c\end{array}$ & & & $\begin{array}{l}\text { s. }>10 \mathrm{CI} \\
\text { vs }>10 \mathrm{C}\end{array}$ & $\begin{array}{r}0.025 \\
=0.8\end{array}$ & \\
\hline
\end{tabular}

This table shows statistically significant correlation between TTP and APD and CD

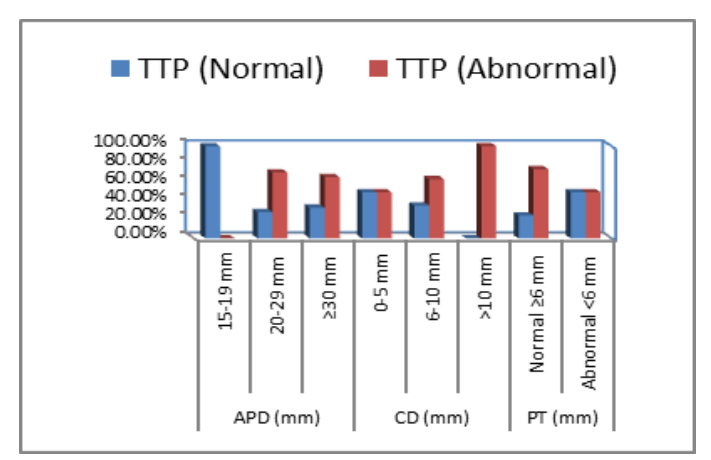

Fig. (3): Bar chart showing correlation between TTP and ultrasound parameters in the study group.

Table (8): Correlation between $\mathrm{T} 1 / 2(\mathrm{~min})$ and ultrasound parameters in the study group.

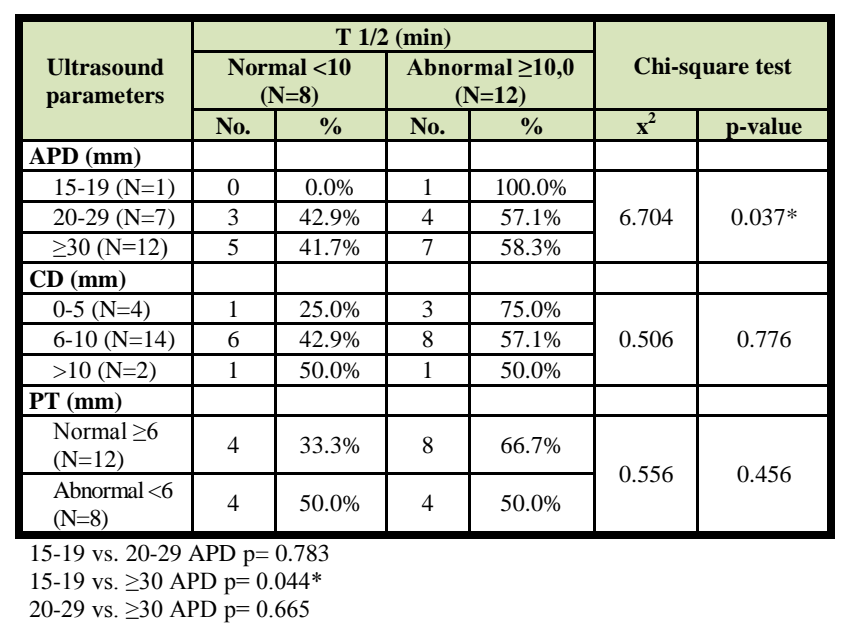

This table shows statistically significant correlation between T 1/2 and APD. 


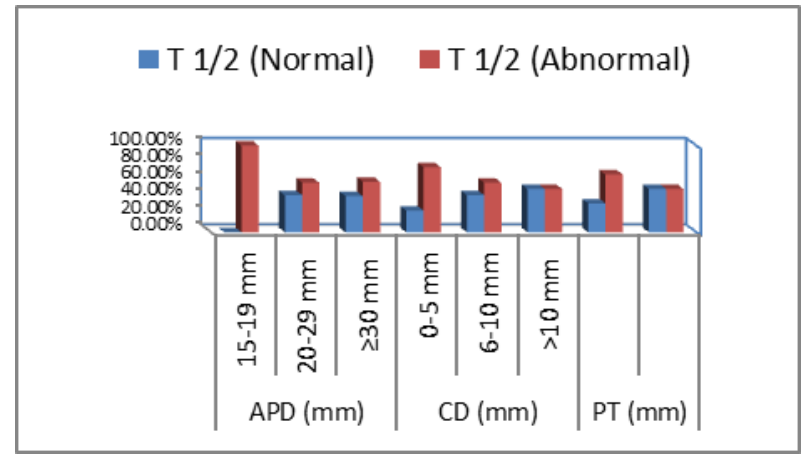

Fig.(4): Bar chart showing correlation between $\mathrm{T} \quad 1 / 2$ (min) and ultrasound parameters in the study group.

Table (9): Showing correlation between quality of renal drainage and ultrasound parameters in the study group.

\begin{tabular}{|c|c|c|c|c|c|c|}
\hline \multirow{3}{*}{$\begin{array}{l}\text { Ultrasound } \\
\text { parameters }\end{array}$} & \multicolumn{4}{|c|}{ Quality of renal drainage } & \multirow{2}{*}{\multicolumn{2}{|c|}{ Chi-square test }} \\
\hline & \multicolumn{2}{|c|}{$\operatorname{Good}(N=7)$} & \multicolumn{2}{|c|}{ Poor $(\mathrm{N}=13)$} & & \\
\hline & No. & $\%$ & No. & $\%$ & $\mathbf{x 2}$ & p-value \\
\hline \multicolumn{7}{|l|}{ APD (mm) } \\
\hline $15-19(\mathrm{~N}=1)$ & 1 & $100.0 \%$ & 0 & $0.0 \%$ & \multirow{3}{*}{7.322} & \multirow{3}{*}{$0.029 *$} \\
\hline $20-29(\mathrm{~N}=7)$ & 3 & $42.9 \%$ & 4 & $57.1 \%$ & & \\
\hline$\geq 30(\mathrm{~N}=12)$ & 4 & $33.3 \%$ & 8 & $66.7 \%$ & & \\
\hline \multicolumn{7}{|l|}{ CD (mm) } \\
\hline $0-5(\mathrm{~N}=4)$ & 1 & $25.0 \%$ & 3 & $75.0 \%$ & \multirow{3}{*}{1.633} & \multirow{3}{*}{0.442} \\
\hline 6-10 $(\mathrm{N}=14)$ & 6 & $42.9 \%$ & 8 & $57.1 \%$ & & \\
\hline$>10(\mathrm{~N}=2)$ & 0 & $0.0 \%$ & 2 & $100.0 \%$ & & \\
\hline \multicolumn{7}{|l|}{ PT (mm) } \\
\hline $\begin{array}{l}\text { Normal } \geq 6 \\
(\mathrm{~N}=12)\end{array}$ & 5 & $41.7 \%$ & 7 & $58.3 \%$ & \multirow{2}{*}{0.586} & \multirow{2}{*}{0.444} \\
\hline $\begin{array}{l}\text { Abnormal } \\
<6(\mathrm{~N}=8)\end{array}$ & 2 & $25.0 \%$ & 6 & $75.0 \%$ & & \\
\hline
\end{tabular}

$15-19$ vs. $20-29$ APD $p=0.783$

$15-19$ vs. $\geq 30$ APD $p=0.036^{*}$

$20-29$ vs. $\geq 30$ APD $p=0.938$

This table shows statistically significant correlation between quality of renal drainage and APD.

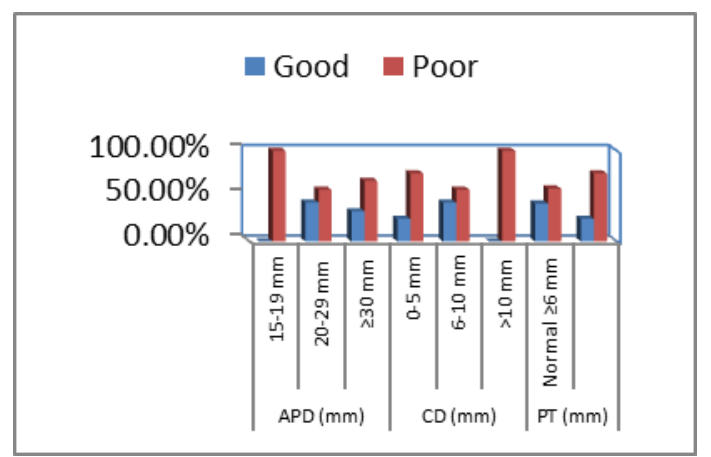

Fig.(5): Bar chart showing correlation between quality of renal drainage and ultrasound parameters in the study group.

\section{DISCUSSION}

Many new developments have deeply influenced the quality of the parameters derived from the renogram. Recent guidelines produced by the
Paediatric Committee of the European Association of Nuclear Medicine have underlined the various pitfalls in acquisition and processing. DRF is accurate and highly reproducible and is one of the main parameters for further management of the paediatric patient Tondeur et al. ${ }^{(7)}$.

It seemed therefore interesting to determine if some US parameters could predict the radionuclide parameters and which ultrasound parameter most influencing the kidney function. The initial step was to grade the severity of hydronephrosis, calyceal dilatation and cortical thinning. Although it was easy for us to classify the importance of hydronephrosis in three groups according to APD, not much information could be found in the literature concerning the two other parameters, and classifications were essentially based on subjective visual criteria combining both calyceal dilatation and cortical thickness Tondeur et al. ${ }^{(7)}$.

Kadioglu et al ${ }^{(\mathbf{8})}$ proposed a diagram giving the normal values of cortical thickness as a function of age. In the present study, we classified calyceal dilatation into three categories and cortical thickness into two, according to our current practice.

\section{Our results:}

\section{First: the relation between the ultrasound parameters and DRF\%:}

In patients with APD $>30 \mathrm{~mm}$, DRF was significantly lower than in those with less pronounced hydronephrosis. it has to be underlined that $100 \%$ of patients with APD $>30 \mathrm{~mm}$ had an abnormal DRF. This is therefore a good indicator of low DRF. Conversely, $84 \%$ of patients with APD $<30 \mathrm{~mm}$ had a normal DRF, strongly suggesting a good negative predictive value. Dhillon ${ }^{(9)}$ in an extensive review of a large population of children diagnosed by hydronephrosis, concluded that "gross dilatation $>50$ $\mathrm{mm}$ ) will inevitably warrant surgery as they will have reduced function initially or will subsequently deteriorate". However, no further data were available on the correlation between pelvic size and the evolution of function. In a series of children with severe hydronephrosis. Koff $\boldsymbol{e t} \boldsymbol{a l} .^{(\mathbf{1 0 )}}$ raised the point of the protective effect of hydronephrosis, that hydronephrosis is generally considered a pathologic process, and especially in infancy is widely viewed as caused by obstruction, potentially injurious to the kidney and in need of expeditious surgical treatment. However a number of clinical and experimental studies suggest exactly the opposite: that hydronephrosis is not pathological but actually a 
compensating mechanism designed to protect the kidney from high pressures and renal damage. Furthermore, because hydronephrosis in the infant involves an already compliant and distensible renal pelvis it appears to be uniquely beneficial. Herein the experimental bases for a counterargument challenging the harmful effects of hydronephrosis are presented. Nitzsche $\boldsymbol{e t} \boldsymbol{a l} .{ }^{(\mathbf{1 1})}$ found that pelvic diameter fails to predict relative renal function in children with unilateral hydronephrosis.

As regards the parenchymal thickness, significant correlation was found between parenchymal thickness and DRF, being the least significant relation in comparison to other ultrasound parameters. Even though the children with parenchymal thinning have a higher risk of impaired renal function, normal DRF was observed in $34 \%$ of the patients, in comparison to Tondeur et al. ${ }^{(7)}$ normal DRF was observed in $42 \%$ of the cases, and $100 \%$ of the cases with abnormal DFR\% was found in $100 \%$ of the cases with abnormal parenchymal thickness in comparison to $58 \%$ by Dhillon ${ }^{(9)}$. This difference may be related to difference in the sample size. The literature related to the value of parenchymal thickness and calyceal dilatation as indicators of renal function is rather poor.

Beland et $\boldsymbol{a l} .^{(12)}$ measured cortical thickness by US in patients with chronic renal disease and found a significant correlation with creatinine-based algorithms. The dispersion of the values around the regression line was, however, Considerable and did not allow the level of function to be predicted on the basis of parenchymal thickness. Lødrup et al ${ }^{(\mathbf{1 3 )}}$ used a similar approach in pigs with chronically diseased kidneys. Instead of parenchymal thickness, they compared the total parenchymal volume with the single kidney glomerular filtration rate. Although the correlation was highly significant, the level of unilateral function was not predictable on the basis of the parenchymal volume. Similar conclusions can be drawn from the data of $\mathbf{N g}$ et al. ${ }^{(\mathbf{1 4})}$ The unilateral parenchymal volume of adult kidneys with chronic obstruction as measured by helical CT is poorly correlated with unilateral creatinine clearance and cannot serve as a surrogate marker of renal function.

It should be underlined that in patients with very severe hydronephrosis, parenchymal thinning does not necessarily reflect functional impairment since cortical volume may simply be spread over a larger surface. This is clear from the early parenchymal images of the renogram: the activity per pixel on the hydronephrotic side might be considerably lower than on the contralateral side, but the number of pixels in the cortical area is higher on the hydronephrotic side, thus resulting in a total number of counts which may be similar to the number observed on the normal side.

Concerning calyceal dilatation, we emphasize that $50 \%$ of the patients with $\mathrm{CD}$ ranging $(0-5 \mathrm{~mm})$ had an abnormal DRF\%, while the $85 \%$ of the patients with CD (5-10 mm) showed abnormal DRF\% and 100\% of the patients with $\mathrm{CD}(>10 \mathrm{~mm})$ showed abnormal DRF\%. So there was a statistically significant difference in DRF between patients with no/mild dilatation and those with severe dilatation $(p=0.027)$. Caldamone $\boldsymbol{e t}$ $\mathbf{a l}{ }^{(\mathbf{1 5})}$ found that no or mild calyceal dilatation was not associated with abnormal DRF while in $39 \%$ of patients severe calyceal dilatation was associated with low DRF. However, in $61 \%$ patients with severe calyceal dilatation was associated with normal DRF, the difference between the results may be caused by different in the sample size or improper preparation as regard adequate hydration. Hell et al. ${ }^{(16)}$ emphasized the clear association between the size of pyelon, calyces, parenchyma thickness and DRF. While Dhillon ${ }^{(9)}$ found that of 75 children with prenatally diagnosed hydronephrosis selected for randomization, all had calyceal dilatation and normal unilateral function.

\section{Second: the relation between ultrasound parameters and quality of renal drainage:}

Concerning the relationship between US parameters and renal drainage as measured from the renographic study. The degree of hydronephrosis and the quality of renal drainage on renography were clearly associated: Our results show significant relation between the quality of the renal drainage and APD where poor renal drainage was found with $66 \%$ of cases with severe hydronephrosis No statistically significant differences are observed between groups 1 and 2 or between groups 2 and 3, with no clear statistical relation between quality of renal drainage and both $\mathrm{CD}$ and PT. Mohammad et $\boldsymbol{a l}^{\left({ }^{(17)}\right.}$ showed that there was a clear association between the size of pyelon, calyces, parenchyma thickness and drainage. Nogarède et $\boldsymbol{a l l}^{\left({ }^{(18)}\right.}$ said that the strong association between pelvic diameter and renal drainage should not be misinterpreted. Although it is true that a diameter below $20 \mathrm{~mm}$ associated with a good drainage practically excludes any 
significant obstruction, the contrary is not true. The presence of poor drainage in a patient with a pelvic diameter $>30 \mathrm{~mm}$ reflects only what is commonly described as the reservoir effect: the tracer arriving in the huge pelvic space has to fill the pelvis completely and will remain for a long time in this space. It is therefore a common error to interpret this poor drainage in terms of severe obstruction necessitating systematic surgical intervention.

\section{Third: the relation between $\mathrm{T} 1 / 2$, time to peak (TTP) and ultrasound parameters;}

Although there was no much more literatures discussing the relation between TTP, T $1 / 2$ and the ultrasound parameters, our results show statistically significant relation between TTP and APD and CD, with $\mathrm{p}$ value $=0.037$ and 0.048 respectively, where no relation was found between TTP and PT with $\mathrm{p}$ value about 0.251 , while there was a significant relation between the $\mathrm{T} 1 / 2$ and APD with $p$ value equals 0.037 , and no significant relation was found between T1/2 and CD or PT. This shows that one cannot replace these radionuclide parameters by the structural ones. Nevertheless, these US parameters remain a rather good screening test for that purpose, since in about $60 \%$ and $65 \%$ of the patients $\mathrm{T} 1 / 2$ and TTP respectively will be abnormal. Alternatively, a normal parenchyma, as well as calyceal dilatation $<10 \mathrm{~mm}$, have a good negative predictive value for impaired TTP and T 1/2.

Fourth: as regards the best sensitive parameter influencing the renal function: our result show a statistically strong correlation between APD and both DRF and quality of the renal drainage.

Fifth: regards treatment strategy, although there is no definitive factor that mandates intervention, the following may be considered as indications for surgical intervention: Ipsilateral UPJ obstruction with less than $40 \%$ of DRF on diuretic renography. Bilateral severe UPJ obstruction with renal parenchymal atrophy. Obstructive pattern on diuretic renography with abdominal mass, urosepsis, or other symptoms (e.g: cyclic flank pain, vomiting). Recurrent UTI under antibiotic prophylaxis. Worsening hydronephrosis on serial ultrasonography.

Upon diagnosis of ureteropelvic junction (UPJ) obstruction, prompt intervention is appropriate to prevent or minimize renal damage. First, prophylactic antibiotic therapy is warranted in cases of moderate-to-severe dilatations because any urinary tract infection (UTI), especially in the neonatal period, dramatically increases the chance of fibrosis and parenchymal damage. Longpre et $\boldsymbol{~ a l}^{\mathbf{( 1 9 )}}$

AP diameter of renal pelvis and differential renal function were the most effective parameters for surgical decision. These parameters can be used for appropriate management of antenatal hydronephrosis, as AP diameter of renal pelvis increases, the likelihood of regression of the hydronephrosis decreases, while indication of surgery increases. Each $1 \mathrm{~mm}$ increase in ultrasonographic measurement increased the surgical risk 1.36-fold Longpre et $_{\text {al }}$ (19) $^{(19}$

Patients with renal function better than $40 \%$ are monitored with repeat renal scans at 3- to 6-month and 12-month intervals, and surgery is performed only if a clear deterioration in renal function is present. In cases where DRF is less than $10 \%$, some recommend the insertion of a nephrostomy tube to determine whether return of function will be sufficient; however, the disadvantages of nephrostomy are the inevitable bacteriuria and the practical difficulty of maintaining a tube in an infant can be considered to relieve recurrent infection or renal hypertension Nguyen et $\boldsymbol{a l}^{\left({ }^{(20)}\right.}$

It is important to recognize that none of the above surgical indications are absolute. There can be a role for observation of a patient with less than $40 \%$ DRF; similarly, there can be cases where nephrectomy is reasonable even if DRF is greater than $10 \%$. All factors must be individualized and interpreted in the context of any other pertinent medical issues that may be present Nguyen et al. ${ }^{(20)}$

\section{CONCLUSION}

At the end of our study, it showed that there is a statically proven correlation between ultrasound parameters and most of the renal scintigraphy parameters especially as regards the DRF. It proves that on the basis of the ultrasound parameters, we can predict the findings of the radionuclide renography and so it can be avoided where it was found that $100 \%$ of patients with APD >30 mm had an abnormal DRF. This is therefore a good indicator of low DRF. Conversely, 84 $\%$ of patients with APD $<30 \mathrm{~mm}$ had a normal DRF, strongly suggesting a good negative predictive value. AP diameter of renal pelvis and differential renal function were the most effective parameters for surgical decision. These parameters can be used for appropriate management of antenatal hydronephrosis. 


\section{REFERENCES}

1. Esteves FP, Taylor A, Manatunga A et al. (2006): 99mTc-MAG3 renography:normal values for MAG3 clearance and curve parameters,excretory parameters, and residual urine volume. A JR Amj Roentgenol., 187(6): W610-7.

2. Esmaeili M, Ghane F, Alamdaran A (2016): Comparison between Diuretic Urography (IVP) and Diuretic Renography for Diagnosis of Ureteropelvic Junction Obstruction in Children. Iran J Pediatr., 26(1): e4293.

3. Montero M, Fontanillo $M$, del Campo V, Pais E, Vela D, Outomuro J (2008): Prognostic value of the ultrasound and diuretic renogram in the evolution of ureteropelvic junction obstruction. Cir Pediatr., 21(2):62-9.

4. Wiener JS, O'Hara SM (2002): Optimal timing of initial postnatal ultrasonography in newborns with prenatal hydronephrosis. J Urol., 168(4 Pt 2):1826- 9.

5. Dunnick NR, Sandler CM, Amis ES (1997): Textbook of Uroradiology. 2nd ed. Philadelphia, Pa: Lippincott Williams \& Wilkins, pp., 6.

6. Weiss DA, Kadakia S, Kurzweil R, Srinivasan AK, Darge K, Shukla AR (2015): Detection of crossing vessels in pediatric ureteropelvic junction obstruction: Clinical patterns and imaging findings. J Pediatr Urol.,(4):173 -175.

7. Tondeur M, Nogarede C, Donoso G, Piepsz A (2013): Inter- and intra-observer reproducibility of quantitative renographic parameters of differential function and renal drainage in children. Scand J Clin Lab Investig., 73:414-21.

8. Kadioglu A (2010): Renal measurements, including length, parenchymal thickness, and medullary pyramid thickness, in healthy children: what are the normative ultrasound values? Am J Roentgenol., 194:509-15.

9. Dhillon HK (1998): Prenatally diagnosed hydronephrosis: the Great Ormond Street experience. Br J Urol., 81(2):39-44.

10. Koff SA, Binkovitz L, Coley B, Jayanthi VR (2005): Renal pelvis volume during diuresis in children with hydronephrosis: implications for diagnosing obstruction with diuretic renography. J Urol., 174(1):303-7.

11. Nitzsche EU, Zimmerhackl LB, Hawkins RA, Stöver B, Frankenschmidt A, Sigmund G et al. (1993): Correlation of ultrasound and renal scintigraphy in children with unilateral hydronephrosis in primary workup. Pediatr Nephrol., 7:138-42.
12. Beland MD, Walle NL, Machan JT, Cronan JJ (2010): Renal cortical thickness measured at ultrasound: is it better than renal length as an indicator of renal function in chronic kidney disease? Am J Roentgenol., 195:146-9.

13. Lødrup AB, Karstoft $K$, Dissing TH, Nyengaard JR, Pedersen M (2008): The association between renal function and structural parameters: a pig study. BMC Nephrol., 9:18.

14. Ng CF, Chan LW, Wong KT, Cheng CW, Yu SC, Wong WS (2004): Prediction of differential creatinine clearance in chronically obstructed kidneys by non-contrast helical computerized tomography. Int Braz J Urol., 30:102-8.

15. Caldamone AA, Palmer JS, Mouriquand $P$ et al. (2010): Ureteropelvic junction obstruction: contemporary approaches to several case scenarios. Dialogues Pediatr Urol.,31:1-7.

16. Hell J, Radulović M, Beatović S, Janković M, Šobić-Šaranović D, Artiko V, Ajdinović B (2017): Diuresis renography and ultrasonography in children with antenatally detected hydronephrosis can support diagnoses and suggest related surgery treatment. https://www.researchgate.net/.../Sequential18F-FDG-PET-CT-imaging-parameters-for-d.

17. Mohammad E, Marjan E, Ali A (2016): Comparison Between Diuretic Urography (IVP) and Diuretic Renography for Diagnosis of Ureteropelvic Junction Obstruction in Children. Iran J Pediatr., 26(1): e4293.

18. Nogarède C, Tondeur M, Piepsz A (2010): Normalized residual activity and output efficiency in case of early furosemide injection in children. Nucl Med Commun., 31:355-8.

19. Longpre M, Nguan A, Macneily AE, Afshar K (2012): Prediction of the outcome of antenatally diagnosed hydronephrosis: a multivariable analysis. J Pediatr Urol., 8:135-9.

20. Nguyen HT, Herndon CD, Cooper C, Gatti J, Kirsch A, Kokorowski P et al. (2010): The Society for Fetal Urology consensus statement on the evaluation and management of antenatal hydronephrosis. J Pediatr Urol., 6:212-231. 